\title{
Boosting Conjugate Addition to Nitroolefins Using Lithium Tetraorganozincates: Synthetic Strategies and Structural Insights
}

\author{
Marzia Dell'Aera, ${ }^{[a],[b]}$ Filippo Maria Perna, ${ }^{[a]}$ Paola Vitale, ${ }^{[a]}$ Angela Altomare, ${ }^{[b]}$ Alessandro Palmieri, ${ }^{[c]}$ \\ Lewis C. H. Maddock, ${ }^{[\mathrm{d}]}$ Leonie J. Bole, ${ }^{[\mathrm{e}]}$ Alan R. Kennedy, ${ }^{[\mathrm{d}]}$ Eva Hevia, ${ }^{\text {[e] }}$ and Vito Capriati*[a],[f] \\ Dedication ((optional))
}

\begin{abstract}
We report the first transition metal catalyst- and ligand-free conjugate addition of lithium tetraorganozincates $\left(\mathrm{R}_{4} \mathrm{ZnLi}_{2}\right)$ to nitroolefins. Displaying enhanced nucleophilicity combined with unique chemoselectivity and functional group tolerance, homoleptic aliphatic and aromatic $\mathrm{R}_{4} \mathrm{ZnLi}_{2}$ provide access to valuable nitroalkanes in up to $98 \%$ yield under mild conditions $\left(0^{\circ} \mathrm{C}\right)$ and short reaction time (30 $\mathrm{min})$. This is particularly remarkable when employing $\beta$ nitroacrylates and $\beta$-nitroenones, where despite the presence of other electrophilic groups, selective 1,4 addition to the $C=C$ is preferred. Structural and spectroscopic studies confirmed the formation of tetraorganozincate species in solution, the nature of which has been a long debated issue, and allowed to unveil the key role played by donor additives on the aggregation and structure of these reagents. Thus, while chelating $N, N, N^{\prime}, N^{\prime}$-tetramethylethylenediamine (TMEDA) and $(R, R)-N, N, N^{\prime}, N^{\prime}$-tetramethyl-1,2-diaminocyclohexane (TMCDA) favour the formation of contacted-ion pair zincates, macrocyclic Lewis donor 12-crown-4 triggers an immediate disproportionation process of $\mathrm{Et}_{4} \mathrm{ZnLi}_{2}$ into equimolar amounts of solvent-separated $\mathrm{Et}_{3} \mathrm{ZnLi}$ and EtLi.
\end{abstract}

\section{Introduction}

Nitroalkenes are established Michael acceptors and unique and versatile building blocks in organic synthesis due to the markedly

[a] Dr. M. Dell'Aera, Dr. P. Vitale, Dr. F. M. Perna, Prof. V. Capriati Dipartimento di Farmacia-Scienze del Farmaco, Università di Bari "A. Moro", Consorzio C.I.N.M.P.I.S., Via E. Orabona 4, I-70125 Bari, Italy

E-mail: vito.capriati@uniba.it

[b] Dr. M. Dell'Aera, Dr. A. Altomare Istituto di Cristallografia (IC-CNR), Via Amendola 122/o, I-70125 Bari, Italy

[c] Prof. A. Palmieri

Dipartimento di Scienze Chimiche, Università di Camerino, Via S Agostino 1, I-62032 Camerino (Italy)

[d] Dr. L. C. H. Maddock, Dr. A. R. Kennedy Department of Pure and Applied Chemistry, University of Strathclyde Glasgow, G1 1XL, UK

[e] Dr. L. J. Bole, Prof. E. Hevia

Department für Chemie und Biochemie, Universität Bern, CH3012, Bern, Switzerland

E-mail: eva.hevia@dcb.unibe.ch

[f] Prof. Vito Capriati

Dipartimento di Chimica, Istituto di Chimica dei Composti Organometallici (ICCOM) - CNR, Università di Bari "A. Moro", Via E. Orabona 4, I-70125 Bari, Italy

CCDC 196165, 1951656, 1977196 and 1977197 contain the supplementary crystallographic data for this paper. These data are provided free of charge by the Cambridge Crystallographic Data Centre.

Supporting information for this article is given via a link at the end of the document. electron-deficient character of the nitro group. The latter can be easily and advantageously transformed into a legion of diverse functionalities including carbonyl derivatives by the Nef reaction, amines by reduction, nitrile oxides, nitriles, hydroxylamines, and imines by other transformations. ${ }^{[1]}$ Several nucleophiles, which include carbon, oxygen, phosphorus, nitrogen, sulfur and cyanide anions, have been hitherto successfully employed. ${ }^{[2]}$ The conjugate addition of various organometallic reagents provides a complementary powerful method for nitro-alkylation. While the effectiveness of these transformations is known to be poor when highly reactive organolithium and Grignard reagents are used, with concomitant undesirable side reactions and low yields which often imply the presence of additives, ${ }^{[3]}$ the alternative use of organozinc reagents as milder and "softer" nucleophiles offers distinct advantages particularly as a result of their lower basicity and broad functional group tolerance. ${ }^{[4]}$

The addition of alkylzinc halides or dialkylzinc reagents to nitroalkenes has been the subject of intensive investigation in the last years, especially with reference to their asymmetric variant. ${ }^{[5]}$ The 1,4-addition process is the normal pathway followed by these reagents, albeit restricted to alkyl-, benzyl-, and allylzinc reagents because of their poor kinetic reactivity. The intriguing replacement of the vinylic nitro group by an alkyl group remains a complication encountered upon treating 2-arylnitroethenes with dialkylzinc compounds in the absence of a Lewis acid and in ethereal solvents. Such an unexpected vinylic $\mathrm{C}-\mathrm{C}$ coupling was first described by Seebach and coworkers in some seminal papers, ${ }^{[6]}$ and has also been noticed to take place by Dilman and coworkers in the copper-catalysed reaction of gem-difluorinated organozinc reagents with $\beta$-nitrostyrenes. ${ }^{[7]}$

Alkali-metal zincate complexes of general composition $R_{3} Z n L i(1)$ and $R_{4} Z n i_{2}$ (2) can be prepared either using the cocomplexation approach from $\mathrm{R}_{2} \mathrm{Zn}$ and $\mathrm{RLi}$ or by reacting $\mathrm{RLi}$ with $\mathrm{ZnCl}_{2}$ in a suitable stoichiometric ratio (Scheme 1). By enabling metal-metal' cooperativities, these systems offer synergistic reactivities which cannot be replicated by their monometallic counterparts. ${ }^{[8]}$

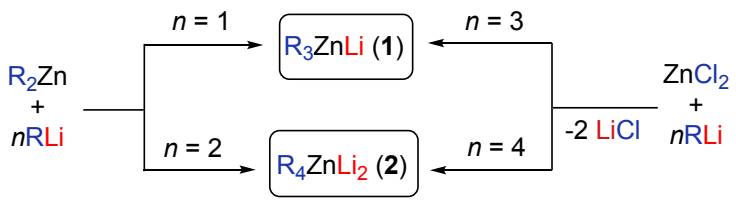

Scheme 1. Formation of lithium zincate complexes 1 and $\mathbf{2}$ by reaction of RL with $\mathrm{R}_{2} \mathrm{Zn}$ or $\mathrm{ZnCl}_{2}$.

Pioneering work by Uchiyama, Sakamoto, and Kondo revealed that, owing to their dianion-type character, the 18electron, tetraorganozincate complexes 2 (also referred to as higher-order zincates), showed a much more pronounced kinetic activity over their triorgano analogues 1 in some fundamental organic transformations such as (i) deprotonative metalations, (ii) 
halogen (or tellurium) zinc exchange reactions followed by trapping reactions with electrophiles or intramolecular epoxide opening, Michael addition and carbozincation reactions, and (iii) copper- and palladium-catalysed $\mathrm{C}-\mathrm{C}$ bond-forming reactions. ${ }^{[9]}$ In contrast to triorganozincates ${ }^{[8,10]}$ however, the applications of tetraorganozincates in transition-metal-catalyst-free $\mathrm{C}-\mathrm{C}$ bondforming processes have received relatively little attention, aside from a recent report by Hevia and coworkers describing the direct arylation of electron-deficient $\mathrm{N}$-heterocyclic compounds using acridine as a case study. ${ }^{[11]}$ Moreover, in spite of the pronounced aptitude of tetraorganozincates towards anion transfer reactions, key questions about their nucleophilic properties and the ability to promote direct conjugate addition to Michael acceptors still remain unanswered.

Filling this important gap in the knowledge, herein we profit on the exceptional functional group tolerance and enhanced nucleophilic power of tetraorganozincates, and report their first applications for regioselective addition to nitroolefins. Key features of this study include (i) no co-ligand, additive or transition metal catalyst is required; (ii) mild reaction conditions $\left(0^{\circ} \mathrm{C}\right)$ and short reaction times (30 min); (iii) high chemoselectivity and broad substrate scope, and (iv) nitroalkanes isolated in up to $98 \%$ yield. Furthermore, structural and spectroscopic studies on these mixed-metal organometallic reagents provide insights on the unique reactivity observed.

\section{Results and Discussion}

As part of our ongoing research towards nucleophilic addition of polar organometallic compounds to carbonyl compounds, ${ }^{[12 a-d]}$ imines, ${ }^{[12 e, f]}$ styrene derivatives, ${ }^{[12 g]}$ amides, ${ }^{[12 h]}$ and nitriles ${ }^{[12 f, i]}$ in the so-called Deep Eutectic Solvents (DESs) ${ }^{[13]}$ and water, we first investigated the addition of $\mathrm{Et}_{2} \mathrm{Zn}(4 \mathrm{a})(1.0 \mathrm{M}$ in hexanes) (1.2 equiv) to conjugated nitroolefin $3 \mathbf{a}(0.5 \mathrm{mmol})$ in two prototypical choline chloride (ChCl)/glycerol (Gly) (1:2 $\mathrm{mol} / \mathrm{mol})$ and $\mathrm{ChCl} / \mathrm{urea}(1: 2 \mathrm{~mol} / \mathrm{mol})$ eutectic mixtures. By running the reaction at room temperature $\left(\mathrm{RT}, 25^{\circ} \mathrm{C}\right)$ and under air, only the starting nitroolefin $3 a$ was quantitatively recovered (Table 1, entries 1,2). The use of D-(-)-fructose as the hydrogen bond donor in combination with $\mathrm{ChCl}(2: 1 \mathrm{~mol} / \mathrm{mol})$, in a sonicator bath $(40 \mathrm{kHz} ; 50 \mathrm{~W}$ ) (due to the increased viscosity of the reaction medium at RT), led to a complete disappearance of olefin 3a with formation of a mixture of 5ac and 6 in a 80:20 ratio, with olefin 6 being the result of the nucleophilic displacement of the nitro group by the ethyl group (Table 1, entry 3 ). It is worth noting that, under the aforementioned conditions, the nucleophilic addition of $\mathbf{4 a}$ took place smoothly within $30 \mathrm{~min}$ reaction time in the absence of any additional ligand and/or a copper source, which are usually essential ingredients for this reaction. ${ }^{[14]}$ DESs are known to act not only as solvents but also as catalytic active species contributing to exalting the electrophilicity/nucleophilicity of a certain reaction partner by hydrogen-bonding interactions. ${ }^{[13 c, 15]}$ Upon switching $\mathbf{4 a}$ for zincate $\mathrm{Et}_{3} \mathrm{ZnLi}(\mathbf{4 b})$ in the fructose-based eutectic mixture, the 5ac/6 ratio became 90:10 (full conversion) (Table 1, entry 4). Similar results were obtained at RT with the use of the more nucleophilic zincate complex $\mathrm{Et}_{4} \mathrm{ZnLi}_{2},(\mathbf{4 c})$ prepared by mixing 2 equiv of EtLi ( $0.5 \mathrm{M}$ benzene/cyclohexane) with $\mathrm{Et}_{2} \mathrm{Zn}$ (see Supporting Information) (Table 1, entry 5).

Remarkably, the one-shot, rapid addition of $4 \mathrm{c}$ to $\mathbf{3 a}$, performed at $0{ }^{\circ} \mathrm{C}$, under nitrogen and with no additional solvents, produced adduct $\mathbf{5 a c}$ in $98 \%$ isolated yield as the sole product (Table 1, entry 6). Of note, either the strict exclusion of air or lowering the temperature to $0{ }^{\circ} \mathrm{C}$, proved to be crucial to increase even more the yield of $\mathbf{5 a c}$ and to completely suppress the formation of 6 as a by-product (contrasting with the results observed when the reaction is carried out at RT; Table 1, entry 7 ).
Organozinc compounds are known to be able to initiate the formation of alkyl radicals through the reaction with oxygen, ${ }^{[16]}$ and the alkyl substitution at the vinylic carbon is supposed to take place via a radical pathway. ${ }^{[7]}$ This could explain our own results. Under the best conditions of Table 1 (entry 6), addition of a substoichiometric amount of $\mathbf{4 c}$ ( 0.6 equiv) to $3 \mathbf{a}$ still provided only $\mathbf{5 a c}$ in $89 \%$ yield (Table 1, entry 8 ), whereas $\mathbf{4 b}$ (1.2 equiv) furnished a mixture of 5 ac and 6 in a 91:9 ratio (Table 1, entry 9).

It should be noted that the formation of tetraorganozincate complexes in solution, as postulated by Uchiyama and Sakamoto, ${ }^{\left[{ }^{9]}\right.}$ where $\mathrm{Zn}$ is bonded to four anionic ligands, has previously been a debated issue because of the strong coulombic repulsion, which should make these species thermodynamically unfavored. ${ }^{[17]}$ Contrastingly, DFT studies on systems containing $t-$ Bu groups suggest that the disproportionation of $t-\mathrm{Bu}_{3} \mathrm{ZnLi}$ into $t$ $\mathrm{Bu}_{4} \mathrm{ZnLi}_{2}$ and $t-\mathrm{Bu}_{2} \mathrm{Zn}$ is favoured in THF. ${ }^{[18]}$ More recently, Koszinowski has pointed out that "the formulas $\mathrm{LiZnR}_{3}$ and $\mathrm{Li}_{2} \mathrm{ZnR}_{4}$ refer to the overall composition of the reactive mixtures but do not necessarily reflect the stoichiometry of the actual species present in solution". ${ }^{19]}$ Detailed NMR spectroscopic studies carried out by Berger and Mobley with ${ }^{13} \mathrm{C}$-enriched reagents, indeed, allowed to ascertain that addition of 2 equiv of MeLi to $\mathrm{Me}_{2} \mathrm{Zn}$ generated an equilibrium mixture of $\mathrm{Me}_{3} \mathrm{ZnLi}$ and $\mathrm{Me}_{4} \mathrm{ZnLi}$, though strongly shifted toward the former product. ${ }^{[20]}$ Thus, in some cases, the reactive species could be the higher energy tetraorganozincate complex, which would explain the chemical reactivities reported by Uchiyama and Sakamoto for these complexes ${ }^{[9]}$ and also our own results discussed herein.

Table 1. Addition of organozinc species 4 to nitroolefin $3 a$ under different conditions. $^{[\mathrm{a}]}$

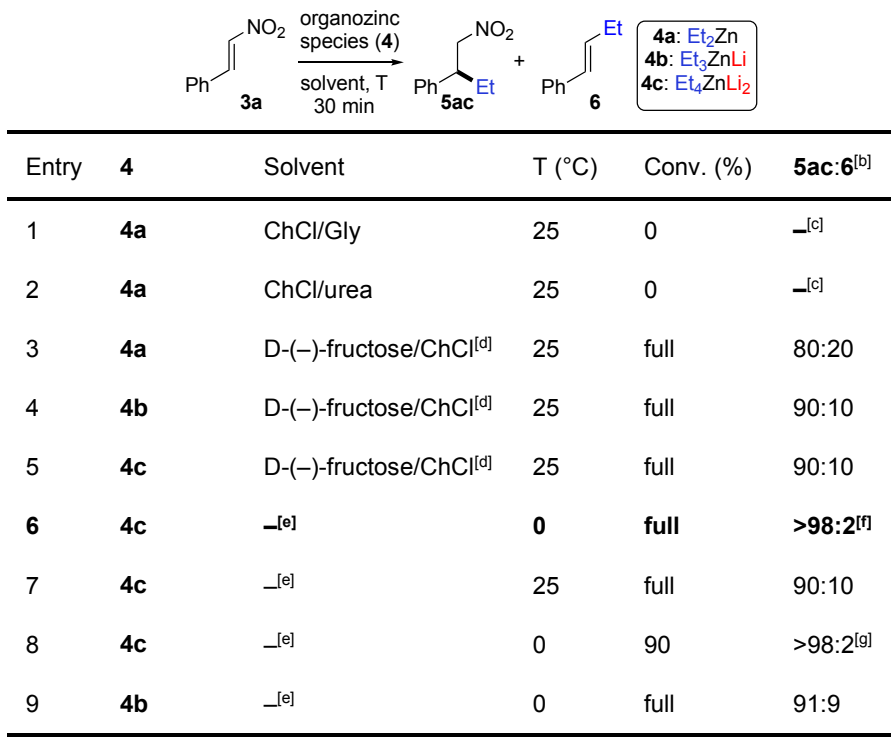

[a] Reaction conditions: $1.0 \mathrm{~g}$ DES per $0.5 \mathrm{mmol}$ of $3 \mathrm{a}$; ChCl/Gly $(1: 2 \mathrm{~mol} / \mathrm{mol})$; $\mathrm{ChCl} /$ rea (1:2 $\mathrm{mol} / \mathrm{mol}) ; \mathrm{D}$-(-)-fructose $/ \mathrm{ChCl}(2: 1 \mathrm{~mol} / \mathrm{mol}) ; 1.2$ equiv organozinc species. [b] Ratio determined by ${ }^{1} \mathrm{H}$ NMR analysis of the crude reaction mixture. [c] No reaction. [d] Reaction performed in a sonicator bath. [e] With no additional solvents. [f] $98 \%$ yield of isolated product. [g] 4c: 0.6 equiv; $89 \%$ yield of isolated product.

Given the scarcity of structural and spectroscopic data on the constitution of tetraorganozincates, ${ }^{[21]} \mathbf{4 c}$ was isolated as a colourless oil and characterised by multinuclear magnetic resonance studies, including DOSY experiments (see Supporting Information for details). Supporting the formation of $\mathrm{Et}_{4} \mathrm{ZnLi}_{2}$, a distinct quartet at $-0.40 \mathrm{ppm}$ is observed in the ${ }^{1} \mathrm{H}$ NMR spectrum in $\left[\mathrm{D}_{8}\right]$-toluene solution for the $\mathrm{Zn}-\mathrm{CH}_{2}$ groups. Consistent with the increased anionic character, this resonance is significantly shielded compared to that observed for $\mathbf{4 b}$ (at $-0.13 \mathrm{ppm}$ ) and to 
that of $\mathrm{Et}_{2} \mathrm{Zn}$ (at $0.17 \mathrm{ppm}$ ). Contrasting with previous work from Mobley and Berger on $\mathrm{Me}_{4} \mathrm{ZnLi}_{2}$ species (vide supra), low temperature NMR studies of $\mathbf{4 c}$ showed no evidence of a dynamic equilibrium between this tetraorganozincate and $4 \mathbf{b}$ in $\left[D_{8}\right]-$ toluene solutions (even at $-50^{\circ} \mathrm{C}$ ).

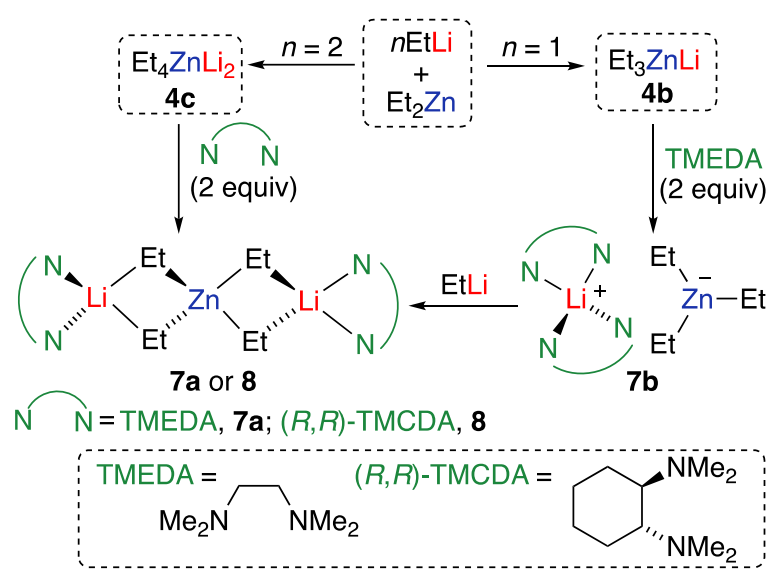

Scheme 2. Synthesis of lithium zincates $\mathbf{4 b}, \mathbf{c}, \mathbf{7 a}, \mathbf{b}$ and 8

In an attempt to trap and structurally characterise a tetraethylzincate intermediate, 2 equiv of the bidentate $\mathrm{N}$-donor ligands TMEDA $\left(N, N, N^{\prime}, N^{\prime}\right.$-tetramethylethylenediamine) and of chiral $\quad(R, R)$-TMCDA $\quad\left[(R, R)-N, N, N^{\prime}, N^{\prime}\right.$-tetramethyl-1,2diaminocyclohexane] were added to in situ prepared solutions of $4 \mathrm{c}$ with the aim of facilitating crystallisation. These reactions led to the isolation of $\left[\mathrm{Et}_{4} \mathrm{ZnLi}_{2}(\mathrm{~N}-\mathrm{N})_{2}\right](\mathrm{N}-\mathrm{N}=\mathrm{TMEDA}, 7 \mathrm{a} ;(R, R)-$ TMCDA, 8) as crystalline solids in 70 and $82 \%$ yields, respectively (Scheme 2). The molecular structures of $7 a$ and 8 were established by X-ray crystallographic studies confirming the presence of the $\mathrm{Et}_{4} \mathrm{ZnLi}_{2}$ fragment (Figures 1 and 2).

Addition of 2 equiv of TMEDA to triorganozincate $4 \mathbf{b}$ furnished $\left[\left\{\mathrm{Li}(\mathrm{TMEDA})_{2}\right\}^{+}\left\{\mathrm{ZnEt}_{3}\right\}^{-}\right] \quad$ (7b) which can be quantitatively transformed into $7 \mathrm{a}$ by addition of 1 equiv of EtLi (Scheme 2). Comparison of the ${ }^{1} \mathrm{H}$ NMR spectra of TMEDA adducts $7 a$ and $7 b$ in $\left[D_{8}\right]$ toluene showed the same trend in the chemical shifts for the $\mathrm{Zn}-\mathrm{CH}_{2}$ groups as that observed for $\mathbf{4 b}$ and 4c (vide supra) ( $\delta$ : -0.25 ppm for $7 a$ vs 0.15 ppm for $7 \mathbf{b}$ ) consistent with the increased anionic character of tetraorganozincate $7 a$. It should also be noted that ${ }^{1} \mathrm{H}$ and ${ }^{7} \mathrm{Li}$ NMR monitoring of solutions of $7 \mathrm{a}$ showed no evidence of disproportionation of this tetraorganozincate into $\mathbf{7 b}$ and EtLi (see Supporting Information for details). X-ray crystallographic studies established a solventseparated ion pair structure for $\mathbf{7 b}$, with $\mathrm{Zn}$ being coordinated to three ethyl groups in a trigonal planar environment with an average $\mathrm{Zn}-\mathrm{C}$ bond distance of $2.036 \AA$, whereas $\mathrm{Li}$ being solvated by two chelating TMEDA ligands in a distorted tetrahedral geometry (Figure 1). This motif is reminiscent of that reported by Stalke for $\left\{\left\{\mathrm{Li}(\text { diglyme })_{2}\right\}^{+}\left\{\mathrm{ZnMe}_{3}\right\}^{-}\right\}$, which is obtained by mixing MeLi and $\mathrm{Me}_{2} \mathrm{Zn}$ in equimolar amounts with diglyme. ${ }^{[22 \mathrm{a}]}$

Contrastingly, $\mathbf{7 a}$ and $\mathbf{8}$ display contacted-ion pair arrangements in the classical Weiss motif mould, ${ }^{[23]}$ with trinuclear arrangements adopting a pseudolinear disposition where each Et bridge connects the central $\mathrm{Zn}$ to an outer $\mathrm{Li}$ atom (Figures 1,2). Since both structures are closely related, only $\mathbf{8}$, which is a rare example of a chiral zincate, will be described here (see Supporting Information for full structural details). As expected, due to this bridging coordination of the Et groups, the $\mathrm{Zn}-\mathrm{C}$ distances in 8 are elongated (mean value, $2.125 \mathrm{~A}$ ) with respect to those found in $\mathbf{7 b}$. Each $\mathrm{Li}$ completes its distorted tetrahedral coordination by binding to a chelating TMCDA donor. DOSY NMR studies are consistent with the retention of this structure in $\left[D_{8}\right]-$ toluene solution (see Supporting Information). As far as we can ascertain, this is the first example of a structurally defined zincate with a chiral donor. ${ }^{[24]}$ It should be noted that both tetraorganozincates $\mathbf{7 a}$ and $\mathbf{8}$ proved to be active towards the transfer of an ethyl group to $\mathbf{3 a}$, although they showed diminished reactivity in comparison to donor-free $\mathbf{4 c}$, thereby affording $\mathbf{5 a c}$ in 76 and $70 \%$ yield, respectively. ${ }^{[25]}$

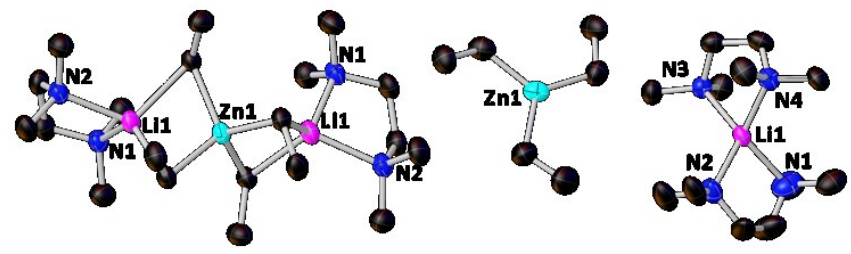

Figure 1. Molecular structures of $\left[\mathrm{Et}_{4} \mathrm{ZnLi}_{2}(\mathrm{TMEDA})_{2}\right]$ (7a) (LHS) and $\left[\left\{\mathrm{Li}(\mathrm{TMEDA})_{2}\right\}^{+}\left\{\mathrm{ZnEt}_{3}\right\}^{-}\right]$(7b) (RHS). Hydrogen atoms are omitted for clarity and thermal ellipsoids are rendered at $50 \%$ probability.

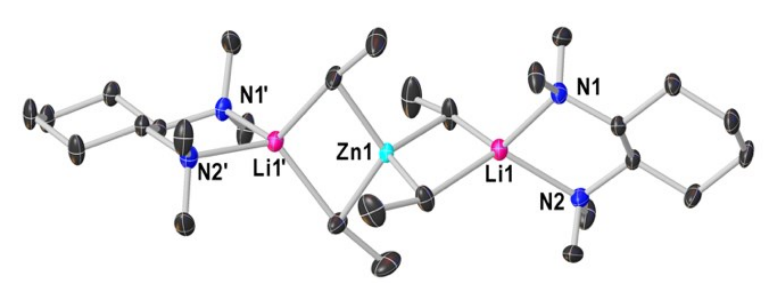

Figure 2. Molecular structure of $\left.\left[\mathrm{Et}_{4} \mathrm{ZnLi}_{2}(R, R)-\mathrm{TMCDA}\right)_{2}\right]$ (8). Hydrogen atoms are omitted for clarity and thermal ellipsoids are rendered at $50 \%$ probability.

Having established the optimal conditions for the chemoselective nucleophilic addition of $\mathbf{4 c}$ to olefin $\mathbf{3 a}$, we sought to capitalise on this process by exploring the scope of this reaction (Table 2). Assorted arylnitroolefins with a methyl substituent (3b), a fluorine atom (3d), electron-withdrawing (chlorine, bromine, trifluoromethyl) (3c, $\mathbf{3 f}, \mathbf{3 g}$ ) or electron-donating groups (MeO) (3e) at the ortho-, meta-, and para-positions could be efficiently reacted with aliphatic tetraorganozincates such as $\mathrm{Et}_{4} \mathrm{ZnLi}_{2}(\mathbf{4 c})$, $n$-Bu $\mathrm{ZnLi}_{2}(\mathbf{4 d}), n-\mathrm{Hexyl}_{4} \mathrm{ZnLi} \mathrm{i}_{2}(\mathbf{4 e}), i-\mathrm{Pr}_{4} \mathrm{ZnLi}_{2}(\mathbf{4 f})$ and $t-\mathrm{Bu}_{4} \mathrm{ZnLi}_{2}$ $(\mathbf{4 g})$ delivering the expected adducts $\mathbf{5 a d}, \mathbf{5 b c}-\mathbf{5 g c}, \mathbf{5 b d}, \mathbf{5 e d}$, $\mathbf{5 b e}, \mathbf{5 b f}$, and $\mathbf{5 a g}$ in very good yields $(65-98 \%)$. Nitroolefins decorated with electron-rich heterocycles (2-furyl, 2-thienyl) (3h,i) also served as competent electrophilic partners, and afforded in the reaction with 4c the adducts $\mathbf{5 h c}$ and $\mathbf{5 i c}$ in $75-85 \%$ yield. Next, we focused on the challenging conjugate addition promoted by an aromatic organozincate reagent like $\mathrm{Ph}_{4} \mathrm{ZnLi}_{2}(\mathbf{4 h}) \cdot{ }^{[11]}$ Arylation of $\beta$-nitrostyrenes has been realised so far only via $\mathrm{Rh}(\mathrm{II})$ - or $\mathrm{Pd}(\mathrm{II})$-catalysed addition reactions with boronic acids or arylsiloxanes. ${ }^{[26]}$ In some preliminary experiments, we found that the addition of $\mathrm{PhLi}$ to nitroolefin 3a gave only a complex mixture, whereas $\mathrm{Ph}_{2} \mathrm{Zn}$ resulted totally unreactive. Highlighting the remarkable synergistic power of these bimetallic reagents, addition of $\mathbf{4 h}$ to $\mathbf{3 a}$ provided adduct $\mathbf{5} \mathbf{a h}$ in $96 \%$ yield. Similarly, the addition of $\mathbf{4 h}$ to nitroolefins $3 \mathrm{~b}-\mathbf{i}$ proceeded smoothly and delivered the desired diarylated adducts $\mathbf{5 b h}-\mathbf{5 i h}$ in $50-70 \%$ yield. Trimethoxy and dimethylamino aryl derivatives $\mathbf{3 j}, \mathbf{k}$ reacted smoothly as well with $\mathbf{4 h}$ to give functionalised nitroalkanes $5 \mathrm{jh}$ and $\mathbf{5 k h}$, each in an excellent yield (98\%). Gratifyingly, heteroaryl organozincate (2-thienyl) $\mathrm{ZnLi}_{2}(\mathbf{4 i})$ also proved to be a competent nucleophilic partner, and in the reaction with nitroolefins $\mathbf{3 f}$ and $\mathbf{3 k}$ led to the addition products $\mathbf{5 f i}$ and $\mathbf{5 k i}$ in satisfactory yields (69$89 \%$ ). These examples of transition metal-free arylation reactions expand even further the synthetic potential of tetraorganozincate reagents as versatile reagents, combining an enhanced nucleophilic power with an exceptional functional group tolerance 
and selectivity, for promoting important $\mathrm{C}-\mathrm{C}$ bond-forming reactions.

Table 2. Nucleophilic addition of tetraorganozincates $\mathbf{4 c - i}$ to nitroolefins $3 \mathbf{a}-\mathbf{k}$ : scope of the reaction. ${ }^{\text {[a] }}$

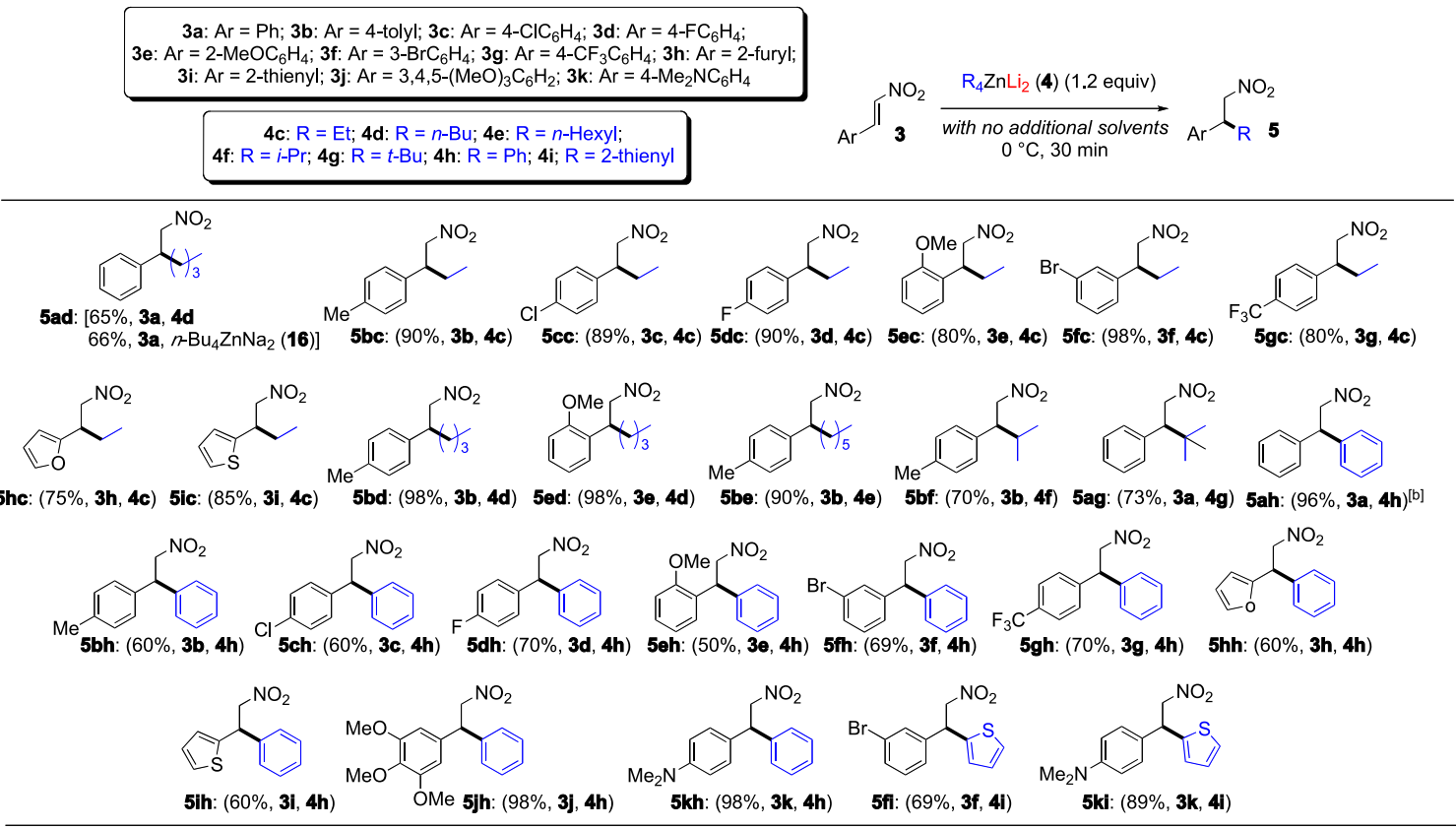

[a] Yields of isolated product. [b] With PhLi: complex mixture; with $\mathrm{Ph}_{2} \mathrm{Zn}$ : no reaction.

Table 3. Nucleophilic addition of $4 \mathbf{c}$ to $\beta$-nitroacrylates $9 \mathbf{a}-\mathbf{e}$ and $\beta$-nitroenones $12 a-c{ }^{[a]}$

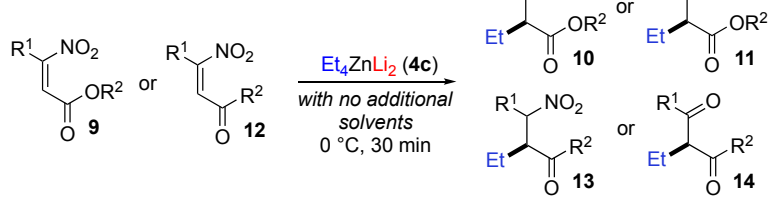

9a: $\mathrm{R}^{1}=\mathrm{PhCH}_{2} \mathrm{CH}_{2}, \mathrm{R}^{2}=\mathrm{Et} ; 9$ b: $\mathrm{R}^{1}=\mathrm{CH}_{3}\left(\mathrm{CH}_{2}\right)_{5}, \mathrm{R}^{2}=i-\mathrm{Pr} ; 9 \mathrm{c}: \mathrm{R}^{1}=\mathrm{CH}_{3}\left(\mathrm{CH}_{2}\right)_{4}, \mathrm{R}^{2}=\mathrm{Et}$; 9d: $R^{1}=E t, R^{2}=\operatorname{Pr} ; 9 e: R^{1}, R^{2}=E t ; 12 a: R^{1}=P_{C H} C_{2} C_{2}, R^{2}=P h$ 12b: $R^{1}=E t, R^{2}=P h ; 12 c: R^{1}=E t, R^{2}=t-B u$

$$
\text { (nt) }
$$

10ac: $70 \%$ [b] 10 bc: $98 \%$ [c] $\quad 10 \mathrm{cc}: 88 \%$ [d] $\quad 10 \mathrm{dc}: 89 \%[$ [c]

$$
\overbrace{O}^{O}
$$

$\begin{array}{llll}11 \text { ec: } 80 \% & 13 a c: 77 \%[\text { [e] } & 14 b c: 80 \% & 14 c c: 70 \%[f]\end{array}$

[a] Yields of isolated product; $0.5 \mathrm{mmol}$ 9, 1.2 equiv $\mathrm{Et}_{4} \mathrm{ZnLi}_{2}(\mathbf{4 c})$. [b] Separable mixture $(60: 40)$ of diastereomers. [c] Inseparable mixture (60:40) of diastereomers. [d] Separable mixture $(43: 57)$ of diastereomers. [e] Separable mixture (45:55) of diastereomers. [f] $\mathrm{In} \mathrm{CD}_{3} \mathrm{Cl}$ solution, $14 \mathrm{cc}$ was found to equilibrate to the corresponding enolic form (see Experimental).

To further quantify the synthetic scope of this protocol, we also investigated the reactivity of tetraorganozincate $4 \mathrm{c}$ towards $\beta$-nitroacrylates, ${ }^{[27 a, b]}$ which are useful building blocks en route to $\beta^{2}$-amino acids, ${ }^{[28]}$ and $\beta$-nitroenones. ${ }^{[27 c, d]}$ As shown in Table 3, the phenylethyl-, the hexyl-, the pentyl- and the ethyl-substituted nitroacrylates $\mathbf{9 a}-\mathbf{d}$ and the aliphatic and aromatic $\beta$-nitroenones 12a-c reacted with good reaction efficiency and high chemoselectivity with $4 \mathrm{c}$ leading to adducts $10 \mathrm{ac}, 10 \mathrm{bc}, 10 \mathrm{cc}$ 10dc, and 13ac (in which either the ester or the carbonyl moiety remained untouched) in 70-98\% yield. In the case of nitroacrylate $9 \mathrm{e}$ and $\beta$-nitroenones $\mathbf{1 2 b , c}$, spontaneous hydrolysis of the nitro group (Nef reaction) took place during the work-up procedure, ${ }^{[29]}$ thereby providing $\beta$-ketoester $11 \mathrm{ec}$ and $\beta$-diketones $14 \mathrm{bc}$ and $14 \mathrm{cc}$, respectively, as the final products in $70-80 \%$ yield.

Since only homoleptic zincates were used in these reactions, we next assessed the selectivity on transfer of the anionic moiety to $3 a$ by using heteroleptic systems which combine simultaneously aryl and alkyl groups (Scheme 3). Using a cocomplexation approach as depicted in Scheme 1, $\mathrm{R}_{2} \mathrm{Ph}_{2} \mathrm{ZnLi}_{2}(\mathrm{R}=$ $\mathrm{CH}_{2} \mathrm{SiMe}_{3}, 4 \mathrm{j}$ ) was prepared in situ by mixing $\mathrm{Ph}_{2} \mathrm{Zn}$ and $\mathrm{RLi}$ in a 1:2 ratio in hexane (Scheme 3 ). The monosilyl $\mathrm{CH}_{2} \mathrm{SiMe}_{3}$ group was chosen as previous studies on zinc-catalysed additions of Grignard reagents to carbonyl compounds from Ishihara have described this group as a dummy ligand with poor transfer capabilities when part of a magnesium triorganozincate complex. ${ }^{[30]}$ The reaction of $4 \mathbf{j}$ with nitroolefin $\mathbf{3 a}$ afforded $\mathbf{5 a h}$ in a modest $20 \%$ yield [contrasting with the almost quantitative yield (96\%) observed when using $\mathrm{Ph}_{4} \mathrm{ZnLi}_{2}$ (4h) as an arylating reagent; Scheme 3, Table 2], being the major product of the reaction the alkyl-substituted adduct 5 aj $(41 \%$ yield $)$ resulting from the transfer of a monosilyl group. The yield for 5 aj could be increased to $88 \%$ when using homoleptic $\left(\mathrm{CH}_{2} \mathrm{SiMe}_{3}\right)_{4} \mathrm{ZnLi} 2$ (4k) While these studies showed poor control of the selectivity when using heteroleptic reagents, they also revealed that by forming more reactive lithium tetra(organo)zincates it is possible to activate, the bulky and usually inert, $\mathrm{CH}_{2} \mathrm{SiMe}_{3}$ group to engage in addition reactions. ${ }^{[31]}$ 


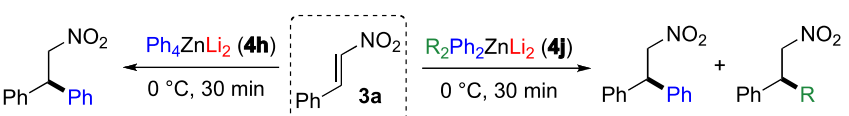

$$
\begin{aligned}
& \text { 5ah: } 96 \% \text { 5ah: } 20 \% \quad \text { 5aj: } 41 \%
\end{aligned}
$$

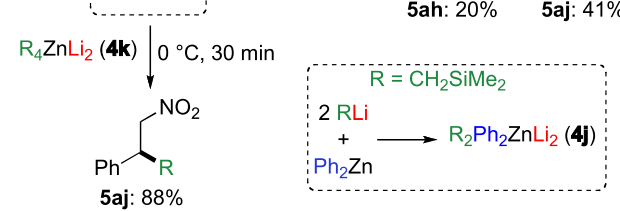

Scheme 3. Assessing arylation/alkylation reactions of $\mathbf{3 a}$ using heteroleptic and homoleptic zincates.

Finally, in an attempt to glean some information on the potential involvement of lithium in these transformations and on whether its possible interaction with the unsaturated organic substrate could also be an important factor on favoring these $\mathrm{C}-\mathrm{C}$ bond-forming processes, $4 \mathrm{c}$ was reacted with $\mathbf{3 a}$ in the presence of 4 equiv of 12-crown-4 (which is known to block the $\mathrm{Li}$ coordination sites). Under these conditions, 5ac was obtained in almost identical yield (95\%) than in the absence of this macrocyclic Lewis donor (98\%), suggesting that $\mathrm{Li}$ plays a secondary role in these alkylations, providing stabilisation to the anionic zincate intermediates. Interestingly, in a recent paper, the fast, direct conjugate addition of organozinc halides to nonenolizable enones observed in 1,2-dimethoxyetane (DME) has been rationalised in terms of the ability of DME to chelate with both its oxygen atoms one of the $\mathrm{Li}$ ions present in the transition state. This contributes to lower the activation energy of the reaction with respect to what has been seen for THF. ${ }^{32]}$

Further investigations on the constitution of $4 \mathbf{c}$, upon the addition of 2 equiv of 12-crown-4, also revealed that a disproportionation process was induced furnishing triorganozincate $\left[\left\{\mathrm{Li}(12-\mathrm{crown}-4)_{2}\right\}^{+}\left\{\mathrm{ZnEt}_{3}\right\}^{-}\right]$(15) as a crystalline solid along with EtLi. X-ray crystallographic studies confirmed the solvent-separated structure of $\mathbf{1 5}$ with the lithium atom being coordinatively saturated, sandwiched between two crown ether ligands, and $\mathrm{Zn}$ coordinated to three ethyl groups forming the same anion present in $\mathbf{7 b}$ (Figure 3 ). It should be noted that while previous work in alkali-metal zincate chemistry has unlocked the key role that donor additives can play in aggregation and structure of these bimetallic systems, ${ }^{[22]}$ the formation of 15 is a rare example where the Lewis donor (12-crown-4) also facilitates a disproportionation process. The similar yields obtained in the formation of $\mathbf{5 a c}$, when $\mathbf{3 a}$ is reacted with tetraorganozincate $\mathbf{4 c}$ or triorganozincate 15, mirror the conversions reported in Table 1 when comparing the reactivities of $\mathbf{4} \mathbf{c}$ and $\mathbf{4 b}$ (vide supra).

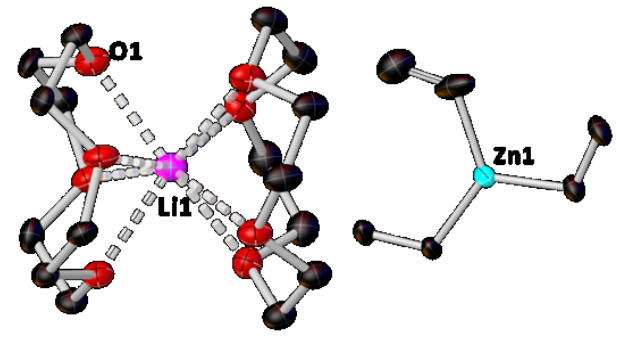

Figure 3. Molecular structure of $\left\{\mathrm{Li}\left(12-\mathrm{crown}_{-} 4\right\}_{2}\left\{\mathrm{ZnEt}_{3}\right\}\right.$ (15). Hydrogen atoms are omitted for clarity and thermal ellipsoids are rendered at $50 \%$ probability.

These findings suggest that the unique reactivity of these bimetallic reagents may be best rationalised in terms of the formation of mono- or dianionic species which should have an enhanced nucleophilic power over that of neutral dialkyl (or diaryl) reagents, with the alkali-metal taking a back-seat in these transformations. Consistent with this interpretation, it should be noted that no noticeable alkali-metal effects were observed when 3a was reacted with sodium zincate $n-\mathrm{Bu}_{4} \mathrm{ZnNa}$ (16) (prepared by co-complexation of 2 equiv of $n-\mathrm{BuNa}$ with $n-\mathrm{Bu}_{2} \mathrm{Zn}$ ) which afforded alkylation product 5 ad in a $66 \%$ yield, almost identical to that observed when using the lithium analog $n-B_{4} Z n L_{2}(4 d)$ (65\%) (Table 2).

\section{Conclusions}

In summary, the first transition metal-catalyst- and ligand-free nucleophilic additions of lithium tetraorganozincates to nitroolefins to provide valuable nitroalkanes are described. These reactions take place smoothly, with high chemoselectivity, under mild conditions $\left(0{ }^{\circ} \mathrm{C}\right)$ and with a broad substrate scope without additional solvents. Structural and spectroscopic studies probing the constitution of these bimetallic systems support the formation of highly nucleophilic lithium tetra- and trialkyl-zincates and highlight the influence that donor additives can have not only in the aggregation and structure of these reagents but also in their stoichiometry. Further extension of this bimetallic research to its asymmetric version is currently being pursued in our laboratories.

\section{Acknowledgements}

This work was carried out under the framework of the National PRIN project "Unlocking Sustainable Technologies Through Nature-Inspired Solvents (Code: 2017A5HXFC_002) and financially supported by MIUR, the Interuniversity Consortium C.I.N.M.P.I.S., the University of Bari (codes: PernaF.18 FondiAteneo15-16, VitaleP.18 Fondi Ateneo 15-16) and the European Research Council (ERC-Stg MixMetApps to EH). The authors are also indebted to Albermarle for the generous gift of chemicals, to Professor Dieter Seebach for valuable, insightful discussions, and to Dr. Alba Rubino and Dr. Lucia Caruso for their contribution to the experimental section.

Keywords: zincate $\cdot$ addition $\cdot$ lithium $\cdot$ nitroolefins $\cdot$ arylation

[1] a) N. Ono in The Nitro Group in Organic Synthesis, (Eds.: H. Feuer and N. Ono), Wiley-VCH, 2001; b) K. Patora-Komisarska, M. Benohoud, H. Ishikawa, D. Seebach, Y. Hayashi, Helv. Chim. Acta 2011, 94, 719; c) A. Z. Halimehjani, I. N. N. Namboothiri, S. E. Hooshmand, RSC Adv. 2014, 4, 48022.

[2] R. Ballini, M. Petrini, Arkivoc 2009, (ix) 195.

[3] In two seminal papers, Tomioka and Yao showed that certain organolithium compounds (e.g., MeLi, n-BuLi, PhLi) could undergo Michael addition to nitroalkenes in ethereal solvents (e.g., $\mathrm{Et}_{2} \mathrm{O}, \mathrm{THF}$ ) at low temperature $\left(-78^{\circ} \mathrm{C}\right)$. Selectivity and chemical yield, however, were highly affected by the substrate concentration. When using $i$-PrLi and $t$ BuLi, the yield of the desired adducts decreased dramatically; see: a) C. F. Yao, K.-H. Kao, J.-T. Liu, C.-M. Chu, Y. Wang, W.-C. Chen, Y.-M. Lin, W.-W. Lin, M.-C. Yan, J.-Y. Liu, M.-C. Chuang, J.-L. Shiue, Tetrahedron 1998, 54, 791; b) T. Yasuhara, K. Nishimura, E. Osafune, O. Muraoka, K. Tomioka, Chem. Pharm. Bull. 2004, 52, 1109; for a recent review, see c) P. Vitale, V. Capriati, S. Florio, F. M. Perna, A. Salomone, Curr. Org Chem. 2017, 21, 190.

[4] a) C. K. Reddy, A. Devasagayaraj, P. Knochel, Tetrahedron Lett. 1996 37, 4495; b) P. Knochel in Handbook of Functionalized Organometallics Wiley-VCH, New York, 2005; c) P. Knochel, N. Millot, A. L. Rodriguez, C. E. Tucker, Org. React. 2001, 58, 417; d) A. Boudier, L. O. Bromm, M. 
Lotz, P. Knochel, Angew. Chem. Int. Ed. 2000, 39, 4414; Angew. Chem. 2000, 112, 4584

[5] a) A. Alexakis, J. Vastra, Tetrahedron Lett. 1997, 38, 7745; b) N. Sewald V. Wendisch, Tetrahedron: Asymmetry 1998, 9, 1341; c) J. P. G Versleijen, A. M. van Leusen, B. L. Feringa, Tetrahedron Lett. 1999, 40, 5803; d) A. Alexakis, C. Benhaim, Org. Lett. 2000, 2, 2579; e) S. Ongeri, U. Piarulli, R. F. W. Jackson, C. Gennari, Eur. J. Org. Chem. 2001, 803; f) U. Eilitz, F. Lebmann, O. Seidelmann, V. Wendisch, Tetrahedron: Asymmetry 2003, 14, 189; g) A. Rimkus, N. Sewald, Synthesis 2004, 1 135; h) C. A. Luchaco-Cullis, A. H. Hoveyda, J. Am. Chem. Soc. 2002 124, 8192; i) A. Duursma, A. J. Minnaard, B. L. Feringa, J. Am. Chem. Soc. 2003, 125, 3700; j) D. Huang, J.-X. Wang, Synlett 2007, 14, 2272.

[6] a) D. Seebach, H. Schäfer, B. Schmidt, M. Schreiber, Angew. Chem. Int Ed. Engl. 1992, 31, 1587; Angew. Chem. 1992, 104, 1680; b) H. Schäfer D. Seebach, Tetrahedron 1995, 51, 2305; for the regioselective, conjugate addition of other nucleophiles (e.g., 2-lithio-1,3-dithianes, sulfur-substituted organolithium reagents, lithium carboxamides, lithium enolates) to nitroolefins, see: c) D. Seebach, H. F. Leitz, Angew. Chem. Int. Ed. Engl. 1969, 8, 983; Angew. Chem. 1969, 81, 1047; d) D. Seebach H. F. Leitz, Angew. Chem. Int. Ed. Engl. 1971, 10, 501; Angew. Chem. 1971, 83, 542; e) D. Seebach, H. F. Leitz, V. Ehrig, Chem. Ber. 1975, 108, 1924; f) D. Seebach, V. Ehrig, H. F. Leitz, R. Henning, Chem. Ber. 1975, 108, 1946

[7] N. S. Kondratyev, V. V. Levin, A. A. Zemtsov, M. I. Struchkova, A. D. Dilman, J. Fluorine Chem. 2015, 176, 89.

[8] a) R. E. Mulvey, Organometallics 2006, 25, 1060; b) R. E. Mulvey, F. Mongin, M. Uchiyama, Y. Kondo, Angew. Chem., Int. Ed. 2007, 46, 3802 Angew. Chem. 2007, 119, 3876; c) R. E. Mulvey, Acc. Chem. Res. 2009 42, 743; d) A. Harrison-Marchand, F. Mongin, Chem. Rev. 2013, 113 7470; e) M. Uchiyama, C. Wang, Top. Curr. Organomet. Chem. 2014 47, 159; f) S. D. Robertson, M. Uzelac, R. E. Mulvey, Chem. Rev. 2019 119, 8332 .

[9] a) M. Uchiyama, M. Koike, M. Kameda, Y. Kondo, T. Sakamoto, J. Am Chem. Soc. 1996, 118, 8733; b) M. Uchiyama, M. Kameda, O. Mishima, N. Yokoyama, M. Koike, Y. Kondo, T. Sakamoto, J. Am. Chem. Soc. 1998, 120, 4934; c) M. Uchiyama, T. Furuyama, M. Kobayashi, Y Matsumoto, K. Tanaka, J. Am. Chem. Soc. 2006, 128, 8404.

[10] a) M. Isobe, S. Kondo, N. Nagasawa, T. Goto, Chem. Lett. 1977, 6, 679; b) C. A. Musser, H. G. Richey, Jr. J. Org. Chem. 2000, 65, 7750.

[11] A. Hernán-Gómez, E. Herd, M. Uzelac, T. Cadenbach, A. R. Kennedy, I Borilović, G. Aromí, E. Hevia, Organometallics, 2015, 34, 2614

[12] a) C. Vidal, J. García-Álvarez, A. Hernán-Gómez, A. R. Kennedy, E. Hevia, Angew. Chem. Int. Ed. 2014, 53, 5969; Angew. Chem. 2014, 126, 6079; b) V. Mallardo, R. Rizzi, F. C. Sassone, R. Mansueto, F. M. Perna, A. Salomone, V. Capriati, Chem. Commun. 2014, 50, 8655; c) L. Cicco, M. J. Rodríguez-Álvarez, F. M. Perna, J. García-Álvarez, V. Capriati, Green Chem. 2017, 19, 3069; d) L. Cicco, S. Sblendorio, R. Mansueto, F. M. Perna, A. Salomone, S. Florio, V. Capriati, Chem. Sci. 2016, 7, 1192; e) C. Vidal, J. García-Álvarez, A. Hernán-Gómez, A. R. Kennedy, E. Hevia, Angew. Chem. Int. Ed. 2016, 55, 16145; Angew. Chem. 2016, 128, 16379; f) G. Dilauro, M. Dell'Aera, P. Vitale, V. Capriati, F. M. Perna Angew. Chem. Int. Ed. 2017, 56, 10200; Angew. Chem. 2017, 129 10334; g) A. Sánchez-Condado, G. A. Carriedo, A. Presa Soto, M. G. Rodríguez-Álvarez, J. García-Álvarez, E. Hevia, ChemSusChem, 2019 12, 3134; h) S. Ghinato, G. Dilauro, F. M. Perna, V. Capriati, M. Blangetti, C. Prandi, Chem. Commun. 2019, 55, 7741; i) M. J. Rodríguez-Álvarez, J. García-Álvarez, M. Uzelac, M. Fairley, C. T. O'Hara, E. Hevia, Chem. Eur. J. 2018, 24, 1720

[13] a) J. García-Álvarez, E. Hevia, V. Capriati, Eur. J. Org. Chem. 2015, 6779; b) J. García-Álvarez, E. Hevia, V. Capriati, Chem. Eur. J. 2018, 24
14854; c) Deep Eutectic Solvents: Synthesis, Properties, and Applications (Eds: D. J. Ramón, G. Guillena), Wiley-VCH, Weinheim, 2019, pp. 1-384.

[14] A. Côté, V. N. G. Lindsay, A. B. Charette, Org. Lett. 2007, 9, 85.

[15] For selected reviews, see: a) M. Francisco, A. van den Bruinhorst, M. C. Kroon, Angew. Chem. Int. Ed. 2013, 52, 3074; Angew. Chem. 2013, 125 3152; b) E. L. Smith, A. P. Abbott, K. S. Ryder, Chem. Rev. 2014, 114, 11060; c) D. A. Alonso, A. Baeza, R. Chinchilla, G. Guillena, I. M. Pastor D. J. Ramón, Eur. J. Org. Chem. 2016, 612; d) N. Guajardo, C. R. Müller, R. Schrebler, C. Carlesi, P. Domínguez de María, ChemCatChem 2016 8, 1020; e) F. M. Perna, P. Vitale, V. Capriati, Curr. Opin. Green Sust. Chem. 2020, 21, 27.

[16] M. P. Bertrand, L. Feray, R. Nouguier, P. Perfetti, J. Org. Chem. 1999 64, 9189-9193

[17] a) L. M. Seitz, T. L. Brown, J. Am. Chem. Soc. 1966, 88, 4140; b) S Toppet, G. Slinckx, G. Smets, J. Organomet. Chem. 1967, 9, 205; c) L. M. Seitz, B. F. Little, J. Organomet. Chem. 1969, 18, 227.

[18] T. Furuyama, M. Yonehara, S. Arimoto, M. Kobayashi, Y. Matsumoto, M. Uchiyama, Chem. Eur. J. 2008, 14, 10348.

[19] K. Koszinowski, P. Böhrer, Organometallics 2009, 28, 100

[20] T. A. Mobley, S. Berger, Angew. Chem. Int. Ed. 1999, 38, 3070; Angew. Chem. 1999, 111, 3256.

[21] a) D. R. Armstrong, C. Dougan. D. V. Graham, E. Hevia, A. R. Kennedy, Organometallics, 2008, 27, 6063; b) W. Clegg, B. Conway, E Hevia, M. D. McCall, L. Russo, R. E. Mulvey, J. Am. Chem. Soc. 2009, 131, 2375

[22] a) S. Merkel, D. Stern, J. Henn, D. Stalke, Angew. Chem. Int. Ed. 2009 48, 6350; Angew. Chem. 2009, 121, 6468; b) D. R. Armstrong, H. S Emerson, A. Hernan-Gomez, A. R. Kennedy, E. Hevia, Dalton Trans. 2014, 43, 14229.

[23] E. Weiss, Angew. Chem. Int. Ed. 1993, 32, 1501; Angew. Chem. 1993 105, 1565.

[24] For an example of a zincate containing a chiral anionic amide group see: D. R. Armstrong, W. Clegg, S. H. Dale, J. García-Álvarez, R. W. Harrington, E. Hevia, G. W. Honeyman, A. R. Kennedy, R. E. Mulvey, C. T. O'Hara, Chem. Comm. 2008, 187.

[25] We have also ascertained that adduct 5ac, resulting from the transfer of an Et group from complex $\mathbf{8}$ to $\mathbf{3 a}$, is a racemic mixture.

[26] Selected examples: a) R. Li, Z. Wen, N. Wu, Org. Biom. Chem. 2016, 14 11080; b) R. Lerebours, C. Wolf, Org. Lett. 2007, 9, 2737; c) Z.-Q. Wang, C.-G. Feng, S.-S. Zhang, M.-H. Xu, G.-Q. Lin, Angew. Chem. Int. Ed. 2010, 49, 5780; Angew. Chem. 2010, 122, 5916; d) K.-C. Huang, B. Gopula, T.-S. Kuo, C.-W. Chiang, P.-Y. Wu, J. P. Henschke, Org. Lett. 2013, 15, 5730 .

[27] a) R. Ballini, S. Gabrielli, A. Palmieri, Curr. Org. Chem. 2010, 14, 65; b) S. Gabrielli, E. Chiurchiù, A. Palmieri, Adv. Synth. Catal. 2019, 361, 630 c) R. Ballini, D. Fiorini, A. Palmieri, Tetrahedron Lett. 2004, 45, 7027; d) A. Palmieri, S. Gabrielli, R. Ballini, Green Chem. 2013, 15, 2344.

[28] J.-H. Fang, J.-H. Jian, H.-C. Chang, T.-S. Kuo, W.-Z. Lee, P.-Y. Wu, H.L. Wu, Chem. Eur. J. 2017, 23, 1830.

[29] R. Ballini, M. Petrini Adv.Synth. Catal. 2015, 357, 2371.

[30] M. Hatano, O. Ito. S. Suzuki, K. Ishihara, J. Org. Chem. 2010, 75, 5008

[31] For another example showing the poor transfer ability of monosilyl groups to unsaturated organic molecules using organozinc reagents, see: E. Hevia. A. R. Kennedy, J. Klett, Z. Livingstone, M. D. McCall Dalton Trans. 2010, 39, 520.

[32] G. Casotti, G. Ciancaleoni, F. Lipparini, C. Nieri, A. Iuliano, Chem. Sci. 2020, 11, 257 


\section{Organozinc chemistry}

\section{COMMUNICATION}

The metamorphosis of organozinc reagents! Transforming neutral $\mathrm{R}_{2} Z n$ into nucleophilic $\mathrm{R}_{4} \mathrm{ZnLi}_{2} \quad$ zincate complexes enabled chemoselective alkylation/arylation of nitroolefins to give 1,4-addition adducts in up to $98 \%$ yield. Structural and spectroscopic investigations confirmed the dianionic-type nature of these species and the key role of donor additives in their aggregation and structure.

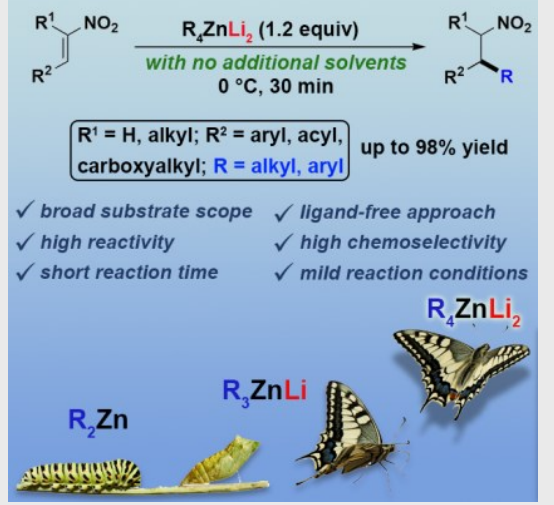

Marzia Dell'Aera, Filippo Maria Perna, Paola Vitale, Angela Altomare,

Alessandro Palmieri, Lewis C. $\mathrm{H}$. Maddock, Leonie J. Bole, Alan R. Kennedy, Eva Hevia, * Vito Capriati*

Page No. - Page No.

Boosting Conjugate Addition to Nitroolefins Using Lithium Tetraorganozincates: Synthetic Strategies and Structural Insights 